\title{
Nonlinear control for an optimized grid connection system of renewable energy resources
}

\author{
Mohammed El Malah, Abdellfattah Ba-Razzouk, Elhassane Abdelmounim, Mhamed Madark \\ Department of Applied Physics, MISI Laboratory, FST Settat, University Hassan $1^{\text {st }}$ Settat, Morocco
}

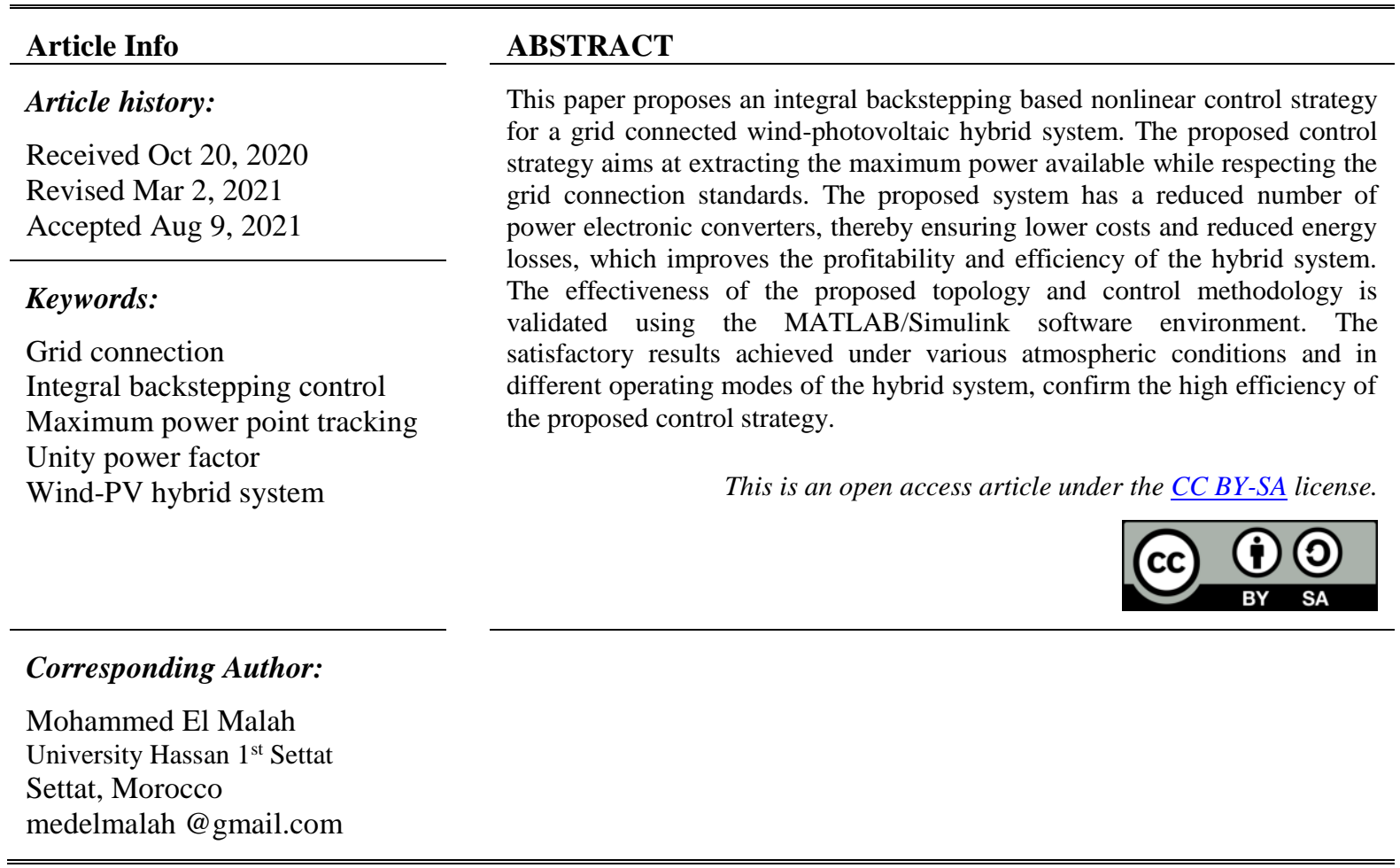

\section{INTRODUCTION}

Growing international concerns about climate change and the ongoing dangers associated with the exploitation of nuclear power generation technology are leading to new advances in electricity generation from renewable resources. Due to their environmental friendliness and sustainability, wind and solar energies have become widespread energy resources. But these resources are intermittent in nature, making it difficult to ensure a stable and continuous energy supply. The problem can be overcome by efficiently integrating local energy storage elements, but their limited life time adds an additional ongoing production cost.

Hybridization of renewable resources, especially if they are complementary in terms of availability, is an adequate solution to the problem of intermittency. Hybridization also reduces the number of power converters, which are typically dedicated to each resource, thus allowing efficient use of the installed converters. In addition, direct grid connection, whilst providing an intelligent energy management system to match production to use, is an appropriate approach to minimize or eliminate storage devices altogether.

A considerable academic literature on renewable power generation (RPG) is mainly devoted to their sizing, reliability, cost analysis, and energy management [1]-[6], whilst others contribute to their modelling and control techniques [7]-[9]. A maximum power point tracking (MPPT) controller is required to make the best use of the available energy. To this end, intensive work has been carried out on MPPT control of photovoltaic and wind energy systems [10]-[15], but most of proposed control methods are based on conventional methods, such as perturbation and observation or incremental conductance algorithms and proportional-integral (PI) controllers. In fact, these systems are nonlinear and the PI controller is designed for linear systems. The high performance of nonlinear controllers compared to conventional controllers has already been reported by several comparative studies [16], [17], and various nonlinear controllers have been 
proposed as efficient alternatives to conventional MPPT controls [18]-[22]. On another note, grid codes, such as the FERC standard interconnection agreements for wind and other alternative technologies (order No. 661-A), require that a power factor greater than 0.95 be maintained at the point of interconnection. For this purpose, power factor control for grid-connected RPG systems is of paramount importance [23]-[25].

Against this background, the present work proposes an efficient nonlinear control of a low-cost gridconnected PV-wind hybrid configuration. This paper assumes that the grid connection process, as detailed in [26], [27], has already been done. The proposed hybrid system components and their models are presented in the next section, and on the basis of these models nonlinear control laws are developed in the third section. The results of the simulations undertaken to validate and evaluate the proposed control strategy are presented in the fourth section, and a brief conclusion is given in the last section.

\section{SYSTEM ELEMENTS AND THEIR MODELS}

The proposed hybrid system configuration is illustrated in Figure 1. Using common electronic power converters, this configuration offers considerable savings in initial and operating costs (less energy loss). In fact, DC/DC and DC/AC converters dedicated to the conversion of photovoltaic (PV) energy are eliminated and the double fed induction generator (DFIG) converters will take care of the conversion of PV energy.

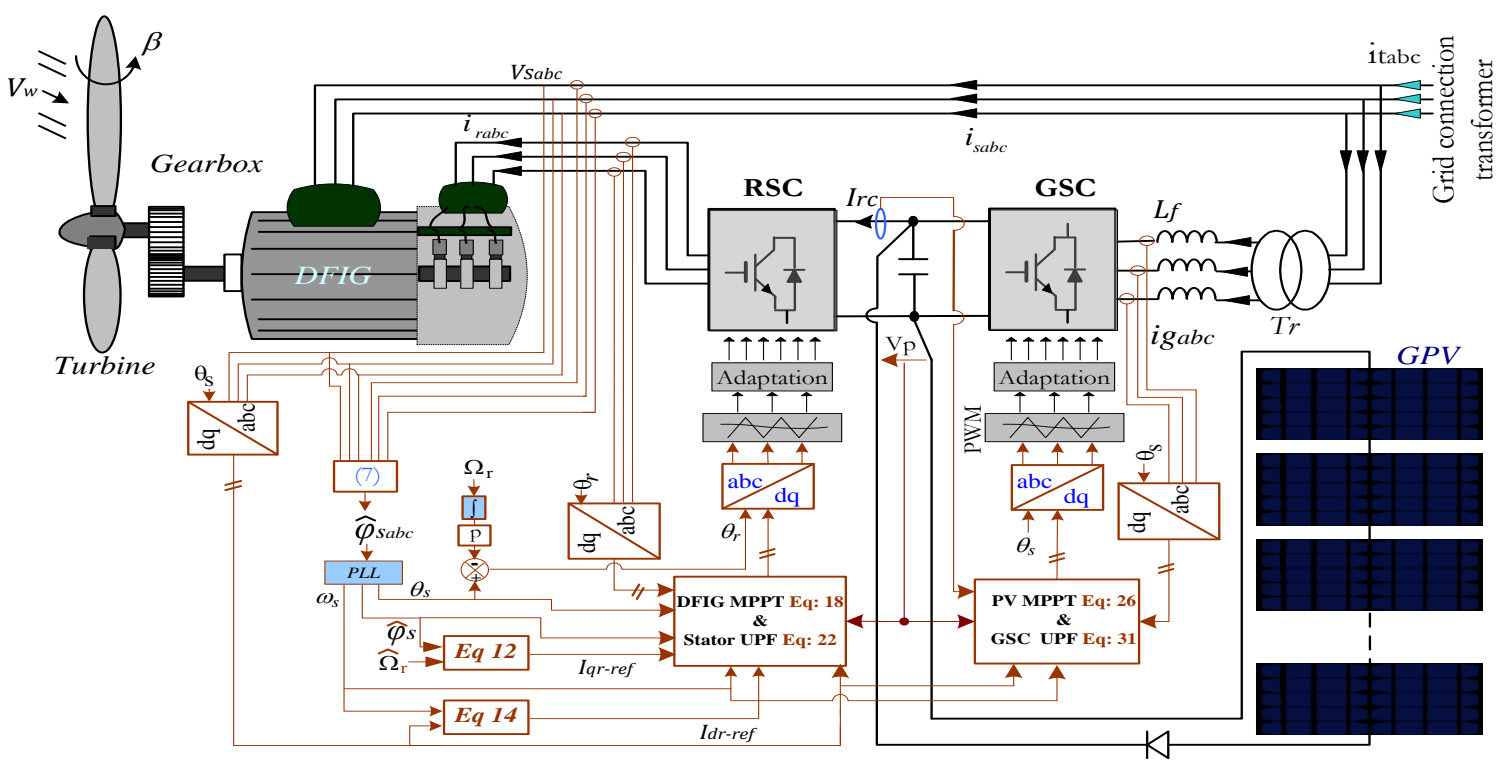

Figure 1. Schematic diagram of the proposed hybrid system and control strategy

\subsection{Aerodynamic energy conversion}

The aerodynamic power, $P_{a e r}$, captured by the turbine used in the proposed system is given by [18]:

$$
P_{a e r}=\frac{1}{2} C_{p}(\lambda, \beta) \rho \pi R^{2} V_{w}^{3}
$$

$$
\begin{gathered}
C_{p}(\lambda, \beta)=c_{1}\left(\frac{c_{2}}{\lambda_{i}}-c_{3} \beta-c_{4}\right) e^{\frac{-c_{5}}{\lambda_{i}}}+c_{6} \lambda \\
\lambda=\frac{\Omega_{t} R}{V_{w}} ; \quad \frac{1}{\lambda_{i}}=\frac{1}{\lambda+0.08 \beta}-\frac{0.035}{\beta^{3}+1}
\end{gathered}
$$

where: $C_{p}$ is the wind turbine power coefficient; $\rho$ is the air density; $R$ is the blade radius (in metres); $V_{w}$ is the wind speed (in $\mathrm{m} / \mathrm{s}$ ); $\Omega_{t}$ is the turbine angular speed (in $\mathrm{rad} / \mathrm{s}$ ); $\lambda$ is the tip speed ratio and $\beta$ is the blade pitch angle (in degrees). With $c_{l}=0.5176 ; \mathrm{c}_{2}=116 ; \mathrm{c}_{3}=0.4 ; \mathrm{c}_{4}=5 ; \mathrm{c}_{5}=21$ and $c_{6}=0.0068$. Figure 2 shows the characteristics of the wind turbine's power coefficient at different values of the blade pitch angle. The pitch control protects the turbine against turbulence and excessive overload, under normal conditions $\beta=0$.

\subsection{Photovoltaic energy conversion}

The mathematical expressions for the single-diode equivalent circuit of the PV cell are given by [19]: 


$$
I_{c e l l}=I_{p h}-I_{s}\left[e^{\left(q \frac{V_{c e l l}+I_{c e l l} R_{S}}{\gamma K T}\right)}-1\right]-\frac{V_{c e l l}+I_{c e l l} R_{S}}{R_{s h}}
$$

$$
\mid \begin{aligned}
& I_{p h}=\frac{E}{E_{\text {ref }}}\left[I_{s c}+K_{i}\left(T-T_{\text {ref }}\right)\right] \\
& I_{s}=I_{r s}\left(\frac{T}{T_{\text {ref }}}\right)^{3} e^{\frac{-q E_{g 0}}{\gamma K}\left(\frac{1}{T}-\frac{1}{T_{\text {ref }}}\right)}
\end{aligned}
$$

where: $I_{\text {cell }}$ is the current crossing the PV cell; $V_{\text {cell }}$ is the PV cell voltage; $I_{p h}$ is the photocurrent; $I_{s}, I_{r s}$ and $I_{s c}$ are the cell saturation current, the reverse saturation current and the short-circuits current; $q$ is the electron charge; $R_{s h}$ and $R_{s}$ are the intrinsic parallel and series resistors; $\mathrm{K}$ is the Boltzmann constant; $\gamma$ is the diode ideality factor; $E$ is the solar irradiance; $E_{r e f}$ is the reference irradiance $\left(1 \mathrm{~kW} / \mathrm{m}^{2}\right) ; T$ is the temperature on absolute scale; $T_{\text {ref }}$ is the reference temperature $(298,15 \mathrm{~K}) ; K_{i}$ is the short-circuit current temperature coefficient and $E_{g 0}$ is the band-gap energy of the cell. Therefore, with a photovoltaic generator (PVG) consisting of $\mathrm{Np}$ strings in parallel, each string consists of Ns cells in series, the expression of the PVG current $\left(I_{p v}\right)$ as a function of its voltage $\left(V_{p v}\right)$ can be derived as follows:

$$
\left\{\begin{array}{l}
V_{p v}=N_{s} V_{\text {cell }} \\
I_{p v}=N_{p} I_{\text {cell }}
\end{array} \Rightarrow I_{p v}=N_{p} I_{p h}-N_{p} I_{s}\left[e^{\left(q \frac{N_{p} V_{p v}+N_{s} I_{p v} R_{S}}{\gamma K T N_{p} N_{S}}\right)}-1\right]-\frac{N_{p} V_{p v}+N_{S} I_{p v} R_{S}}{N_{S} R_{S h}}\right.
$$

In this paper, a PVG made up of seventeen SM55 panels connected in series is considered. Electrical specifications for one panel are given in [21]. The Power-Voltage characteristics of the PVG under solar irradiance change are shown in Figure 3. The coordinates of the maximum power points shown in the zoomed-in parts of Figures 2 and 3 will be used to verify the simulation results.



Figure 2. $C_{p}(\lambda)$ characteristics for different values of $\beta$



Figure 3. Power characteristics of the GPV

\subsection{State space representation}

All measured 3-phase quantities are transformed into the stator-flux oriented dq-reference frame as shown in

Figure 1. The DC-bus voltage, which is also the PVG voltage $\left(V_{p v}\right)$, is governed by the following equation:

$$
\frac{d V_{p v}}{d t}=\frac{1}{C}\left(K_{d g} I_{d g}+K_{q g} I_{q g}+I_{p v}-I_{r c}\right)
$$

where $C$ is the DC-bus capacitor; $I_{r c}$ is the DC-current absorbed by the rotor side converter (RSC); $I_{d g}$ and $I_{q g}$ are the d-axis and q-axis components of the current absorbed by the grid side converter (GSC); $K_{d g}$ and $K_{q g}$ are the GSC control signal components in d-q frame.

In the synchronous dq-frame, the stator flux vector is aligned on the d-axis. Assuming that the stator flux magnitude is constant and the small drop in the stator resistance voltage is negligible, the stator voltage vector is also considered practically aligned on the q-axis of the dq-frame [27]-[29]. According to (4) and [18] an overall state space representation of the hybrid system under consideration is given by:

$$
\left\{\begin{array}{lll}
\frac{d I_{d r}}{d t}=\omega_{r} I_{q r}-\frac{R_{r}}{L_{r} \sigma} I_{d r}+\frac{V_{p v}}{L_{r} \sigma} K_{d r} & \\
\frac{d I_{q r}}{d t}=-\omega_{r} I_{d r}-\frac{\omega_{r} M}{\omega_{s} L_{s} L_{r} \sigma} V_{s}-\frac{R_{r}}{L_{r} \sigma} I_{q r}+\frac{V_{p v}}{L_{r} \sigma} K_{q r} & & \omega_{s}=\frac{d \theta_{s}}{d t} \\
\frac{d I_{d g}}{d t}=\omega_{s} I_{q g}-\frac{R_{f}}{L_{f}} I_{d g}-\frac{V_{p v}}{L_{f}} K_{d g} & \omega_{r}=\frac{d \theta_{r}}{d t}=\omega_{s}-p \Omega_{r} \\
\frac{d I_{q g}}{d t}=-\omega_{s} I_{d g}-\frac{R_{f}}{L_{f}} I_{q g}+\frac{V_{g}}{L_{f}}-\frac{V_{p v}}{L_{f}} K_{q g} & \\
\frac{d V_{p v}}{d t}=\frac{1}{C}\left(K_{d g} I_{d g}+K_{q g} I_{q g}+I_{p v}-I_{r c}\right) &
\end{array}\right.
$$


where $I_{d r}$ and $I_{q r}$ are the rotor current components; $L_{s}$ and $L_{r}$ are the stator and rotor inductances; $R_{r}$ is the resistance of rotor windings; $\theta_{s}\left(\theta_{r}\right)$ are the angular position of the $\mathrm{d}-\mathrm{q}$ frame with respect to the reference frame attached to the stator (rotor); $M$ is the stator-rotor magnetizing inductance; $\sigma$ is the leakage coefficient $\left(\sigma=1-M^{2} / L_{s} L_{r}\right) ; K_{d r}$ and $K_{q r}$ are the RSC control signal components; $R_{f}$ and $L_{f}$ are the resistance and the inductance of the L-filter; $V_{s}$ is the q-axis component of the stator voltage; $V_{g}$ is the quadrature component of the transformer $\left(\mathrm{T}_{\mathrm{r}}\right)$ secondary voltage, see Figure 1 , with $V_{g}=m V_{s} ; m$ is the transformation ratio of $T_{r}$. The electromagnetic torque is expressed in the synchronous frame as:

$$
T_{e m}=-p \frac{M}{L_{s}} \varphi_{s} I_{q r}
$$

where $p$ is the number of pole pairs per phase in the DFIG stator windings; $\varphi_{s}$ is the d-axis component of the stator flux.

\section{DESIGN OF HYBRID SYSTEM CONTROLLERS}

The grid voltage is assumed to be stable, and the stator flux is estimated as:

$$
\hat{\varphi}_{s_{i}}=\int\left(v_{s_{i}}-R_{s} i_{s_{i}}\right) d t ; \quad i \in\{a, b, c\}
$$

The angular frequency $\left(\omega_{s}\right)$ and the phase angle $\left(\theta_{s}\right)$ of the synchronous $\mathrm{d}-\mathrm{q}$ frame are generated using a three-phase phase-locked loop (PLL), as shown in Figure 4 [18], [21].

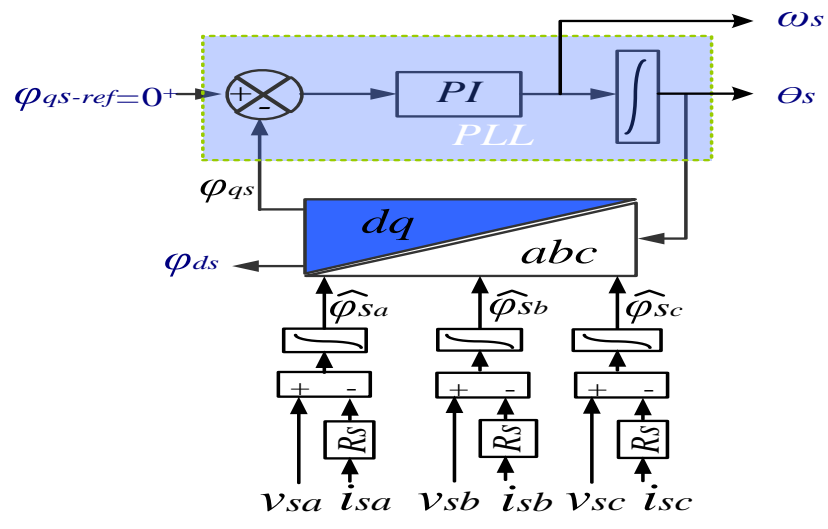

Figure 4. Block diagram of the PLL

The RSC controller is designed to track the maximum power point (MPP) of the wind turbine and to inject the stator power with near unity power factor (UPF). The GSC controller is designed to track the MPP of the PVG and to maintain the reactive power injected by the GSC close to zero in Figure 1.

\subsection{Designation of the hybrid system outputs and their references}

The DFIG rotor dynamics obey Newton's second law for rotational dynamics, thus:

$$
J \frac{d \Omega_{r}}{d t}=T_{a / r}+T_{e m}-F \Omega_{r}
$$

where, Jand $F$ are the total inertia and total viscosity coefficient (turbine and DFIG), $T_{a / r}$ is the aerodynamic torque applied to DFIG rotor, $T_{e m}$ is the algebraic value of the DFIG electromagnetic torque and $\Omega_{r}$ its rotor speed. Operating the wind turbine at the maximum power point (i.e. $\lambda=\lambda_{\text {opt }}$ and $C_{p}=C_{p_{-} \max }$ ) means that:

$$
P_{a e r}=P_{a e r_{\max }} \stackrel{(1)}{\Rightarrow} P_{a e r_{\max }}=\frac{1}{2} C_{p_{-} \max } \rho \pi R^{2}\left(V_{w}\right)^{3}=\frac{1}{2} C_{p_{-} \max } \rho \pi R^{2}\left(\frac{\Omega_{t} R}{\lambda_{\text {opt }}}\right)^{3}
$$

Then, the optimal aerodynamic torque, $T_{a / r_{-} \text {opt }}$, is such that: 


$$
T_{a / r_{-} o p t}=\frac{P_{a e r_{\max }}}{\Omega_{r}} \stackrel{\left(\Omega_{r}=G \Omega_{t}\right)}{=} T_{a / r_{-} o p t}=K_{o p t} \Omega_{r}^{2}
$$

where $K_{o p t}=\frac{\rho \pi R^{5} C_{p \_ \text {max }}}{2 G^{3} \lambda_{o p t}{ }^{3}} ; G$ is the gearbox ratio and $\Omega_{r}$ is the DFIG rotor speed. The optimal electromagnetic torque $\left(T_{\text {em_opt }}\right.$ ) and then the reference of the first output (q-axis rotor current; $I_{q r}$ ) are derived as:

$$
\begin{aligned}
& \stackrel{(8)}{\Rightarrow} T_{\text {em_opt }}=F \Omega_{r}-T_{a / r_{-} \text {opt }} \\
& \stackrel{(6) \&(10)}{=} I_{q r_{r e f}}=\frac{L_{s}}{p M \varphi_{s}}\left(K_{o p t} \Omega_{r}^{2}-F \Omega_{r}\right) \quad \Rightarrow \frac{d I_{q r_{r e f}}}{d t}=\frac{L_{s}}{p M \varphi_{s}} \frac{d \Omega_{r}}{d t}\left(2 K_{o p t} \Omega_{r}-F\right)
\end{aligned}
$$

The reactive powers are expressed as a function of $I_{d r}$ and $I_{d g}$ (second and third outputs) as [18]:

$$
\left\{\begin{array}{l}
Q_{s}=\frac{V_{s}^{2}}{\omega_{s} L_{s}}-\frac{M V_{s}}{L_{s}} I_{d r} \\
Q_{g}=V_{g} I_{d g}
\end{array}\right.
$$

where $Q_{s}$ is the reactive power injected by the DFIG stator; $Q_{g}$ is the reactive powers injected by the GSC. In order to operate the hybrid system at or near UPF, the references of the direct currents are derived as:

$$
\left\{\begin{array}{l}
Q_{s_{o p t}}=\frac{V_{s}{ }^{2}}{\omega_{s} L_{s}}-\frac{M V_{s}}{L_{s}} I_{d r_{r e f}}=0 \\
Q_{g_{o p t}}=V_{q g} I_{d g_{r e f}}=0
\end{array} \quad \Rightarrow \quad \& \quad \begin{array}{l}
I_{d r_{r e f}}=\frac{V_{s}}{M \omega_{s}} \\
I_{d g_{r e f}}=0
\end{array} \quad \& \mid \frac{d I_{d r_{r e f}}}{d t}=\frac{d I_{d g_{r e f}}}{d t}=0\right.
$$

Since the PVG characteristics have a single extremum, as shown in Figure 3, the derivative of the PVG power with respect to its voltage $\left(\frac{\partial P_{p v}}{\partial V_{p v}}\right)$ was chosen as the fourth output of the system with a reference value of zero:

$$
\left(\frac{\partial P_{p v}}{\partial V_{p v}}\right)_{r e f}=0
$$

\subsection{Elaboration of RSC control laws}

Let us define the first error $\varepsilon_{1}$ and a first lyapunov function candidate (LFC) $\mathcal{V}_{1}$ as:

$$
\varepsilon_{1}=I_{q r}-I_{q r_{r e f}} ; \quad \mathcal{V}_{1}=\frac{1}{2} \varepsilon_{1}^{2}+\frac{1}{2} \sigma_{1}^{2}
$$

where $\sigma_{1}=c_{1 i} \int_{0}^{t} \varepsilon_{1}(\tau) d \tau, c_{1 i}$ is the design parameter of the integral action. $\mathcal{V}_{1}$ time-derivative is as:

$$
\frac{d \nu_{1}}{d t}=\varepsilon_{1}\left(\frac{d \varepsilon_{1}}{d t}+c_{1 i} \sigma_{1}\right) \stackrel{(5)}{\Rightarrow} \quad \frac{d \mathcal{V}_{1}}{d t}=\varepsilon_{1}\left(c_{1 i} \sigma_{1}-\omega_{r} I_{d r}-\frac{\omega_{r} M V_{S}}{\omega_{s} L_{s} L_{r} \sigma}-\frac{R_{r}}{L_{r} \sigma} I_{q r}+\frac{K_{q r} V_{p v}}{L_{r} \sigma}-\frac{d I_{q r_{r e f}}}{d t}\right)
$$

The q-axis component of RSC control signal, $K_{q r}$, is chosen as:

$$
K_{q r}=\frac{L_{r} \sigma}{V_{p v}}\left(-c_{1} \varepsilon_{1}-c_{1 i} \sigma_{1}+\omega_{r} I_{d r}+\frac{R_{r}}{L_{r} \sigma} I_{q r}+\frac{\omega_{r} M V_{s}}{\omega_{s} L_{s} L_{r} \sigma}+\frac{d I_{q r_{r e f}}}{d t}\right)
$$

where $c_{1}$ is a strictly positive design parameter. $\mathcal{V}_{1}$ time derivative of the closed-loop system becomes:

$$
\frac{d \nu_{1}}{d t}=-c_{1} \varepsilon_{1}^{2}
$$

Similarly, the error between $I_{d r}$ and its desired value, and a second LFC are defined as follows:

$$
\varepsilon_{2}=I_{d r}-I_{d r_{r e f}} ; \quad \mathcal{V}_{2}=\frac{1}{2} \varepsilon_{2}^{2}+\frac{1}{2} \sigma_{2}^{2}
$$

where $\sigma_{2}=c_{2 i} \int_{0}^{t} \varepsilon_{2}(\tau) d \tau, c_{2 i}$ is the design parameter of the integral action. $\mathcal{V}_{2}$ time-derivative is as: 


$$
\frac{d \mathcal{V}_{2}}{d t}=\varepsilon_{2}\left(\frac{d \varepsilon_{2}}{d t}+c_{2 i} \sigma_{2}\right) \stackrel{(5)}{\Rightarrow} \frac{d \mathcal{V}_{2}}{d t}=\varepsilon_{2}\left(\omega_{r} I_{q r}-\frac{R_{r}}{L_{r} \sigma} I_{d r}+\frac{V_{p v}}{L_{r} \sigma} K_{d r}+c_{2 i} \sigma_{2}-\frac{d I_{d r_{r e f}}}{d t}\right)
$$

Then, the d-axis component of RSC control signal is chosen such that:

$$
K_{d r}=\frac{L_{r} \sigma}{V_{p v}}\left(-c_{2} \varepsilon_{2}-c_{2 i} \sigma_{2}+\frac{R_{r}}{L_{r} \sigma} I_{d r}-\omega_{r} I_{q r}\right)
$$

where $c_{2}$ is a strictly positive design parameter. With the above choice, $\mathcal{V}_{2}$ time derivative becomes:

$$
\frac{d \mathcal{V}_{2}}{d t}=-c_{2} \varepsilon_{2}^{2}
$$

\subsection{Elaboration of GSC control laws}

The error $\varepsilon_{3}$, between $I_{d g}$ and its desired value, and a third LFC are defined as:

$$
\varepsilon_{3}=I_{d g}-I_{d g_{r e f}} ; \quad \mathcal{V}_{3}=\frac{1}{2} \varepsilon_{3}^{2}+\frac{1}{2} \sigma_{3}^{2}
$$

where $\sigma_{3}=c_{3 i} \int_{0}^{t} \varepsilon_{3}(\tau) d \tau ; c_{3 i}$ is the design parameter of the integral action. So, $\mathcal{V}_{3}$ time-derivative is as:

$$
\frac{d V_{3}}{d t}=\varepsilon_{3}\left(\frac{d \varepsilon_{3}}{d t}+c_{3 i} \sigma_{3}\right) \stackrel{(5)}{\Rightarrow} \frac{d V_{3}}{d t}=\varepsilon_{3}\left(\omega_{s} I_{q g}-\frac{R_{f}}{L_{f}} I_{d g}-\frac{V_{p v}}{L_{f}} K_{d g}+c_{3 i} \sigma_{3}\right)
$$

Then, the d-axis component of GSC control signal is chosen as:

$$
A_{1} K_{d g}+A_{2} K_{q g}=B_{1}
$$

where: $A_{1}=\frac{V_{p v}}{L_{f}} ; A_{2}=0 ; B_{1}=c_{3} \varepsilon_{3}+c_{3 i} \sigma_{3}+\omega_{s} I_{q g}-\frac{R_{f}}{L_{f}} I_{d g}$; with $c_{3}$ is a strictly positive design parameter. The above choice guarantees the closed-loop negativity of the $\mathcal{V}_{3}$ time-derivative, which would become:

$$
\frac{d \mathcal{V}_{3}}{d t}=-c_{3} \varepsilon_{3}^{2}
$$

The PV-MPPT error $\varepsilon_{4}$ and a fourth LFC, $\mathcal{V}_{4}$, are defined as:

$$
\varepsilon_{4}=\frac{\partial P_{p v}}{\partial V_{p v}}-\left(\frac{\partial P_{p v}}{\partial V_{p v}}\right)_{r e f}=\frac{\partial P_{p v}}{\partial V_{p v}}=I_{p v}+V_{p v} \frac{\partial I_{p v}}{\partial V_{p v}} ; \quad \mathcal{V}_{4}=\frac{1}{2} \varepsilon_{4}^{2}+\frac{1}{2} \sigma_{4}^{2}
$$

where $\sigma_{4}=c_{4 i} \int_{0}^{t} \varepsilon_{4}(\tau) d \tau ; c_{4 i}$ is the integral action design parameter. $\varepsilon_{4}$ derivative can be formulated as:

$$
\frac{d \varepsilon_{4}}{d t}=f \frac{d V_{p v}}{d t}=\frac{f}{C}\left(K_{d g} I_{d g}+K_{q g} I_{q g}+I_{p v}-I_{r c}\right)
$$

where $f=V_{p v} \frac{\partial^{2} I_{p v}}{\partial V_{p v}{ }^{2}}+2 \frac{\partial I_{p v}}{\partial V_{p v}}$. The time-derivative of $\mathcal{V}_{4}$ is deduced as

$$
\frac{d \mathcal{V}_{4}}{d t}=\varepsilon_{4}\left(\frac{d \varepsilon_{4}}{d t}+c_{4 i} \sigma_{4}\right)=\varepsilon_{4}\left(\frac{f}{c}\left(K_{d g} I_{d g}+K_{q g} I_{q g}+I_{p v}-I_{r c}\right)+c_{4 i} \sigma_{4}\right)
$$

Then, $K_{d g}$ and $K_{q g}$ are chosen in such a way that they satisfy:

$$
A_{3} K_{d g}+A_{4} K_{q g}=B_{2}
$$

where: $A_{3}=\frac{f}{C} I_{d g} ; A_{4}=\frac{f}{C} I_{q g} ; B_{2}=-c_{4} \varepsilon_{4}-c_{4 i} \sigma_{4}+\frac{f}{C}\left(I_{r c}-I_{p v}\right)$ and $c_{4}$ is a strictly positive design parameter. Subsequently, the $\mathcal{V}_{4}$ time-derivative of the closed-loop system becomes:

$$
\frac{d \mathcal{V}_{4}}{d t}=-c_{4} \varepsilon_{4}^{2}
$$

Then, the GSC control signals, $K_{d g}$ and $K_{q g}$, are calculated using (26) and (31):

$$
\left[\begin{array}{l}
K_{d g} \\
K_{q g}
\end{array}\right]=\left[\begin{array}{ll}
A_{1} & A_{2} \\
A_{3} & A_{4}
\end{array}\right]^{-1}\left[\begin{array}{l}
B_{1} \\
B_{2}
\end{array}\right]
$$




\subsection{Overall stability analysis}

Let us define an overall Lyapunov function candidate $\mathcal{V}_{T}$ such as:

$$
\mathcal{V}_{T}=\sum_{i=1}^{4} \mathcal{V}_{i}=\sum_{i=1}^{4} \frac{\varepsilon_{i}^{2}}{2}+\sum_{i=1}^{4} \frac{\sigma_{i}^{2}}{2}
$$

According to (19), (23), (27) and (32), $\mathcal{V}_{T}$ time-derivative of the closed-loop system is:

$$
\frac{d \mathcal{V}_{T}}{d t}=\sum_{i=1}^{4} \frac{d \mathcal{v}_{i}}{d t}=-\sum_{i=1}^{4} c_{i} \varepsilon_{i}^{2}
$$

Thus, $\mathcal{V}_{T}$ is a positive definite function and has a negative definite derivative, therefore the tracking errors are asymptotically stable and converge to zero in Lyapunov's approach.

\section{SIMULATION RESULTS}

The closed-loop hybrid system is modeled in MATLAB-Simulink software in order to assess the performance of the designed controllers. The main parameters used for the simulation are summarized in Table 1. Figure 5 shows Matlab/Simulink diagram for the hybrid system. The solar radiation and wind velocity profiles shown in Figure 6 are used to perform this assessment.

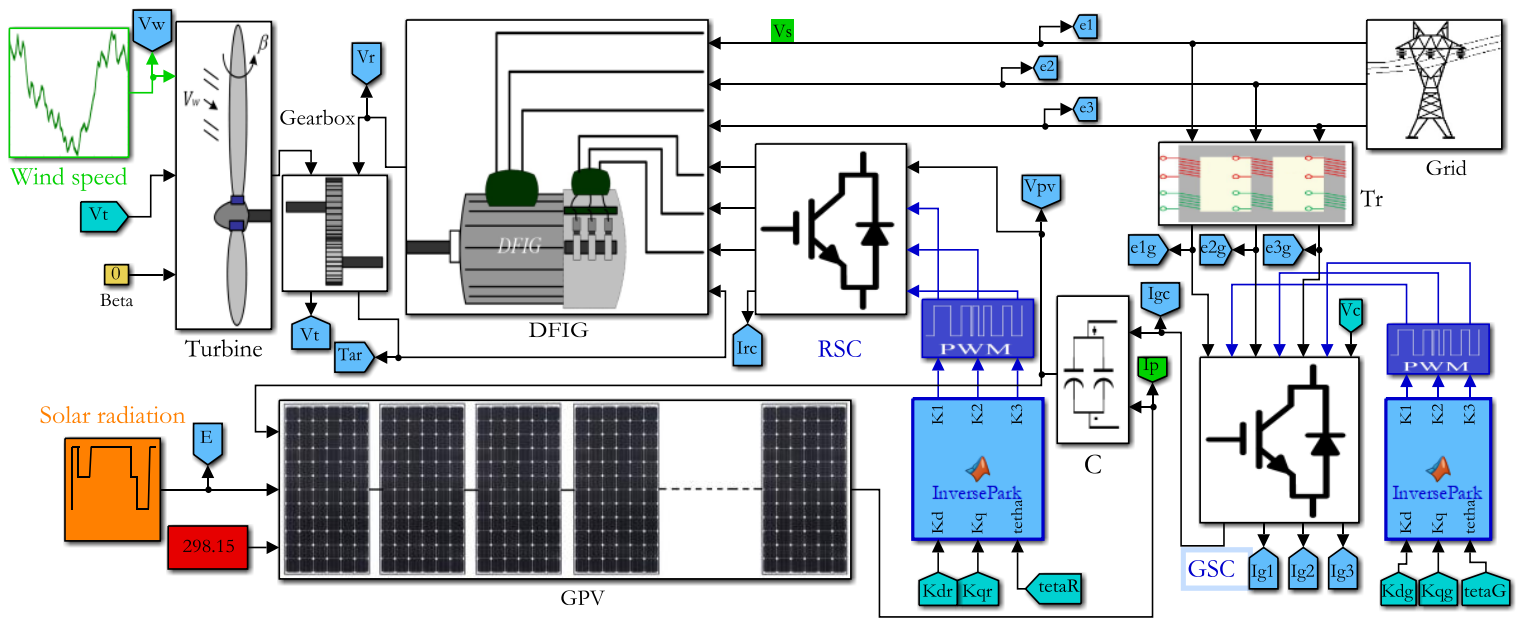

Figure 5. Matlab/Simulink diagram for the hybrid system

\begin{tabular}{|c|c|c|c|c|c|}
\hline & & & \multicolumn{3}{|c|}{ Hybrid system } \\
\hline DFIG rated power & $P_{n}=1 k W$ & Blade radius & $R=0.9 \mathrm{~m}$ & Rotor resistance & $R_{r}=0.88 \Omega$ \\
\hline Line to line voltage & $U_{s}=190 \mathrm{~V}$ & Viscous coefficient & $F=64 \times 10^{-5} \mathrm{Nms} / \mathrm{rad}$ & Stator resistance & $R_{s}=1.01 \Omega$ \\
\hline DFIG pole pair number & $p=3$ & Gearbox ratio & $G=1.3$ & Filter inductance & $L_{f}=12.6 \mathrm{mH}$ \\
\hline Maximal power coefficient & $C_{p \_\max }=4.8$ & Switching frequency & $f_{s}=10 \mathrm{kHz}$ & Mutual inductance & $M=90.1 \mathrm{mH}$ \\
\hline Air density & $\rho=1.22 \mathrm{~kg} / \mathrm{m}^{3}$ & DC-bus capacitor & $C=100 \mu F$ & Rotor inductance & $L_{r}=93.1 \mathrm{mH}$ \\
\hline Optimal Tip speed ratio & $\lambda_{o p t}=8.13$ & Filter resistance & $R_{f}=0.5655 \Omega$ & Stator inductance & $L_{s}=93.1 \mathrm{mH}$ \\
\hline$c_{1}=7 \times 10^{5}$ & $c_{2}=6 \times 10^{5}$ & $c_{2 i}=7 \times 10^{2}$ & $c_{3 i}=20 \times 1$ & $\begin{array}{r}\text { Controllers } \\
c_{4}=10^{5} ;\end{array}$ & $i=50 \times 10^{5}$ \\
\hline
\end{tabular}

Table 1. Parameters of controlled system

A PI controller has been proposed in [29] for controlling the same hybrid system proposed in this paper and the MPPT algorithm "perturbe and observe" (including the PVG power limitation to avoid GSC overload) was used to adjust the PVG voltage. In order to provide a good idea of the proposed control performance, the simulation results obtained using the control strategy proposed in [29] are also presented (as the algorithm for tracking the maximum power of the turbine has not been specified in [29], the q-axis rotor current reference established in this paper has been used in order to provide MPPT control of the wind turbine). 


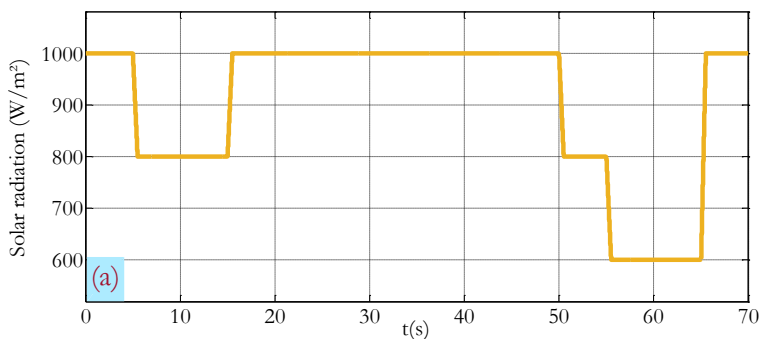

(a)

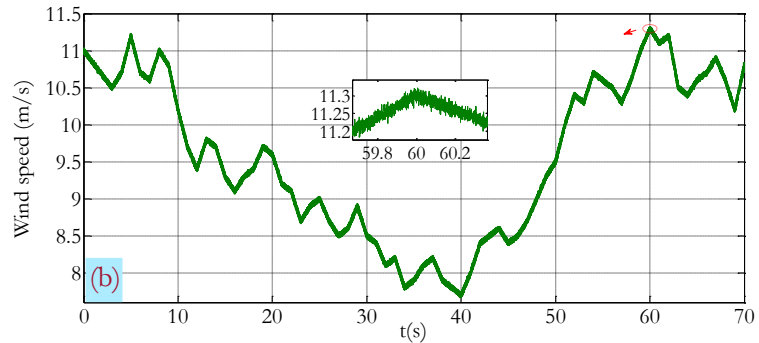

(b)

Figure 6. Environmental conditions, (a) solar radiation profile, (b) wind velocity profile

The first simulation result, Figure 7, clearly shows that the PLL has successfully met its objective (q-axis stator flux is almost zero), and that its outputs are more accurate when used with the integral backstepping control. Figure 8 shows that the d-axis component of the stator voltage (which has been neglected in the design of the controllers) is indeed practically zero; its value does not exceed $0.2 \mathrm{~V}$ with the proposed controller and $\pm 0.6 \mathrm{~V}$ with the PI controller. Figure 9 shows the tracking efficiency of the q-axis rotor current reference provided by the proposed RSC controller, which results in very good tracking performance of the optimal electromagnetic torque, as shown in Figure 10. Figure 11 shows that the power coefficient of the wind turbine has been kept close to its maximum value regardless of variations in wind speed. Figure 12 shows that the d-axis rotor current was kept close to its reference value (with a tracking error of less than $0.5 \mathrm{~A}$ ) and hence the stator reactive power was kept close to zero, as shown in Figure 13. Moreover, the proposed GSC controller has been proven more efficient in controlling the reactive power injected by the GSC close to zero, as shown in Figure 14.

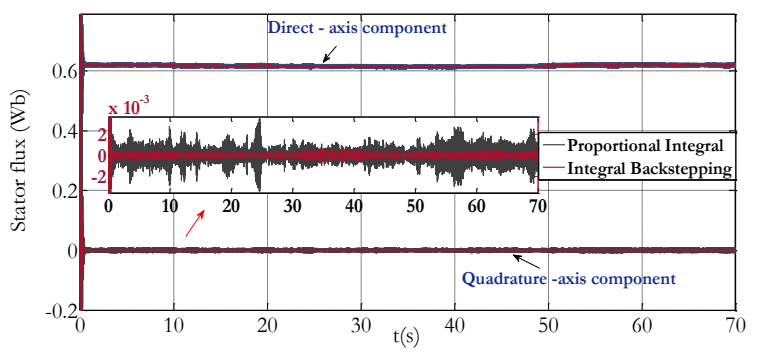

Figure 7. DFIG stator flux



Figure 9. q-axis rotor current

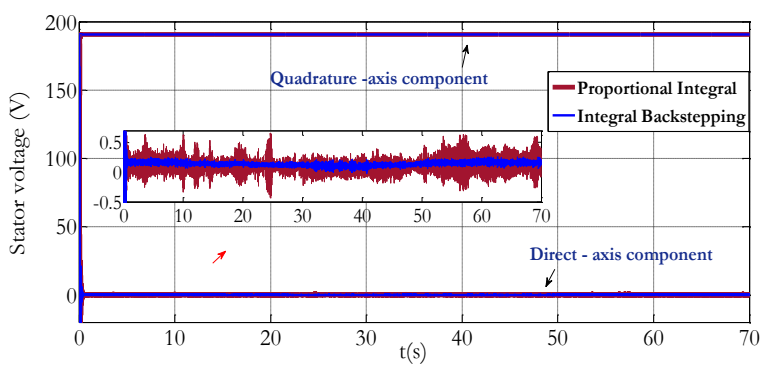

Figure 8. DFIG stator voltage

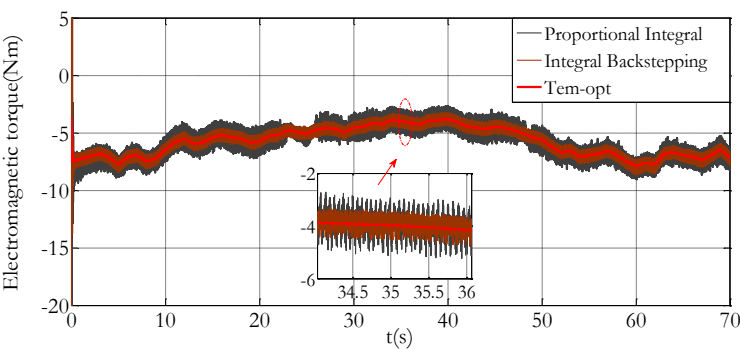

Figure 10. DFIG electromagnetic torque

The total injected power, shown in Figure 15, reveals that the total reactive power is near zero and the active power injected using the proposed controller is greater than that generated using the PI controller. The wind speed profile in Figure 6 was used to evaluate the hybrid system during different operating modes of the DFIG, as can be seen in Figure 16. In the sub-synchronous mode, the power of the PVG is routed through both the GSC and the RSC. Therefore, the active power injected by the GSC becomes lower than that produced by the PVG, as can be seen in the zoomed-in portion of Figure 14. 


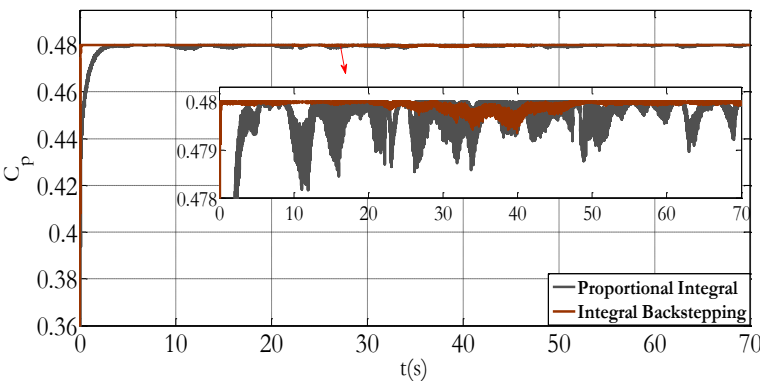

Figure 11. Evolution of the power coefficient

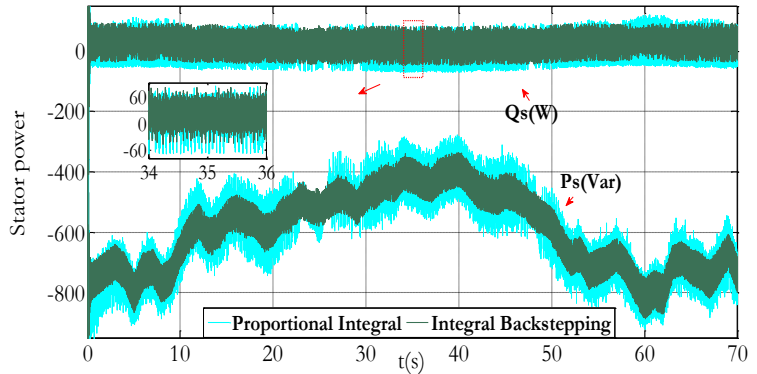

Figure 13. Stator active and reactive powers



Figure 15. Total injected powers



Figure 12. d-axis rotor current

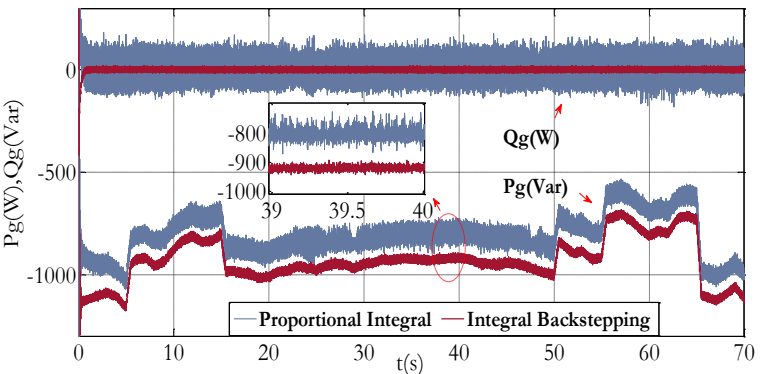

Figure 14. Real and reactive powers injected via GSC

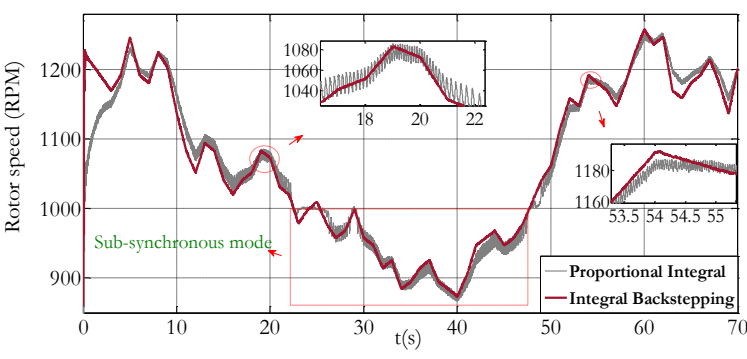

Figure 16. DFIG rotor speed

Figures 17 and 18 show that the PVG voltage, and the PV power generated correspond very precisely to the MPP coordinates of the PVG shown in Figure 3. Figure 19 illustrates that the total current injected using the proposed controller exhibits less fluctuations than that obtained using the PI controller, and that the power factor has been maintained at unity independently of the rotor current behaviour shown in Figure 20.

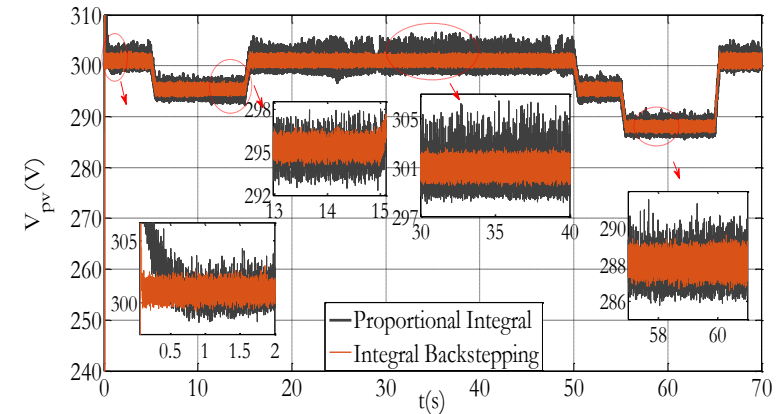

Figure 17. DC-bus voltage behaviour

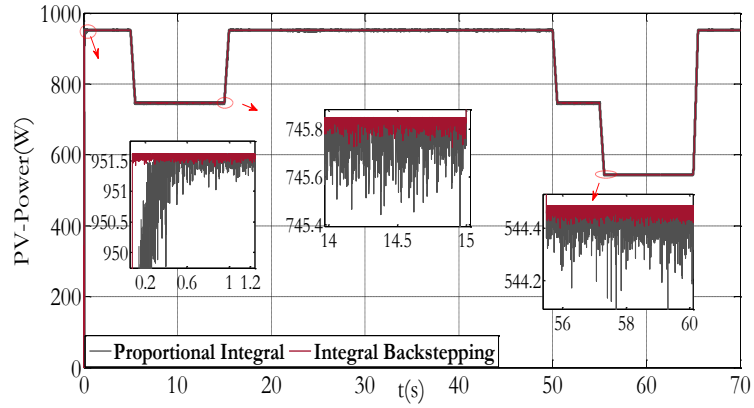

Figure 18. PV power supplied by the PVG 

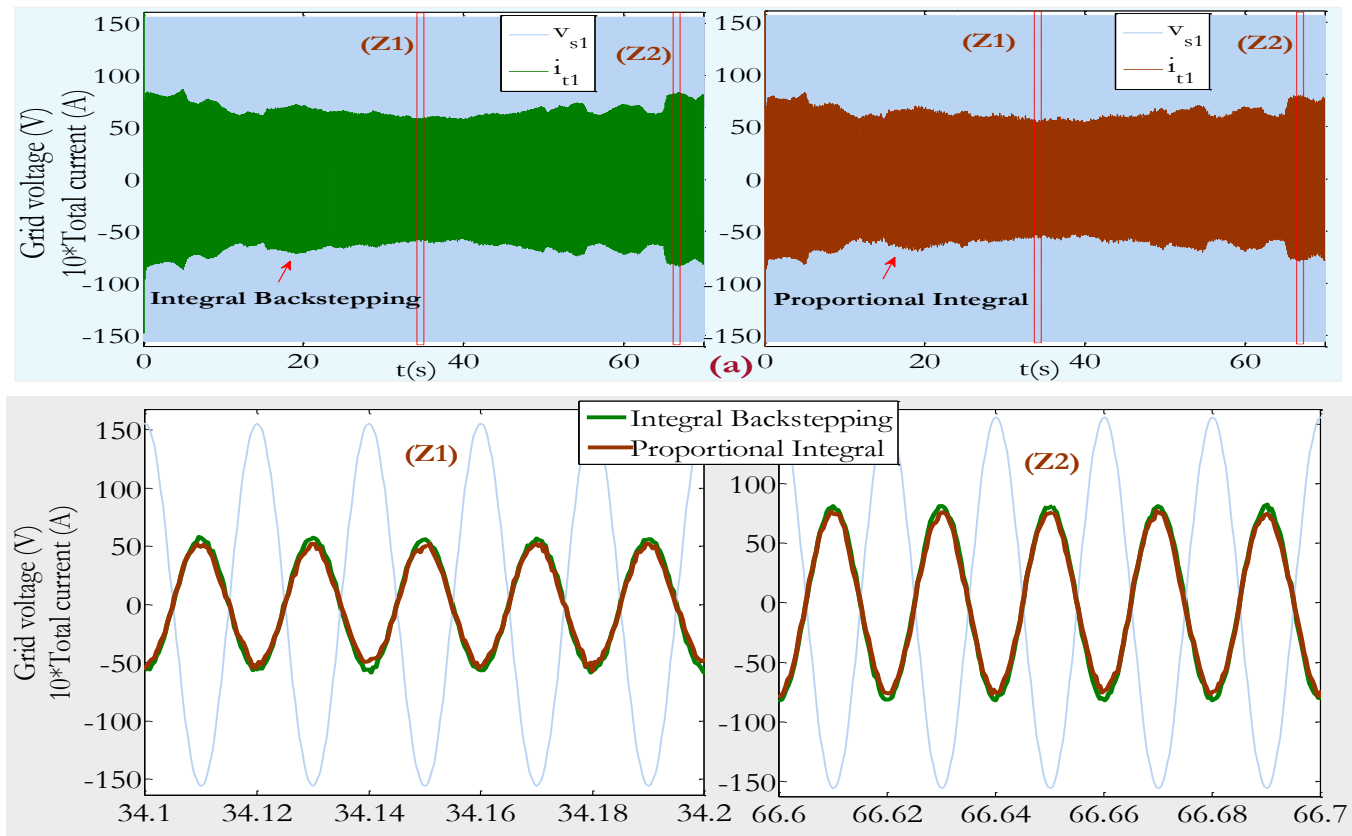

(b)

Figure 19. UPF operation, (a) total current injected into one grid phase, (b) zoomed-in portions of

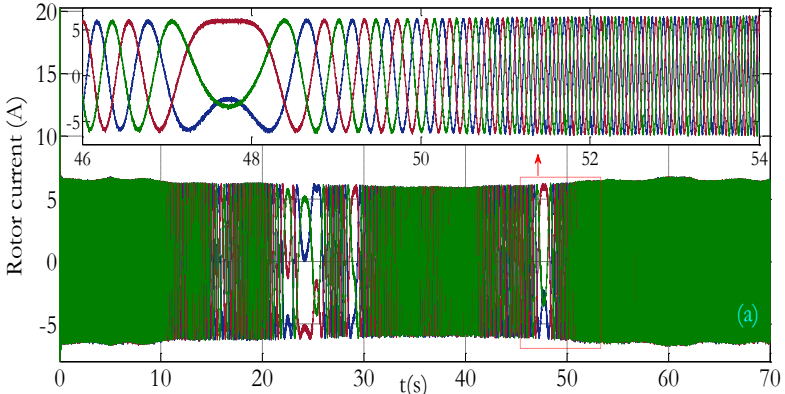

(a)

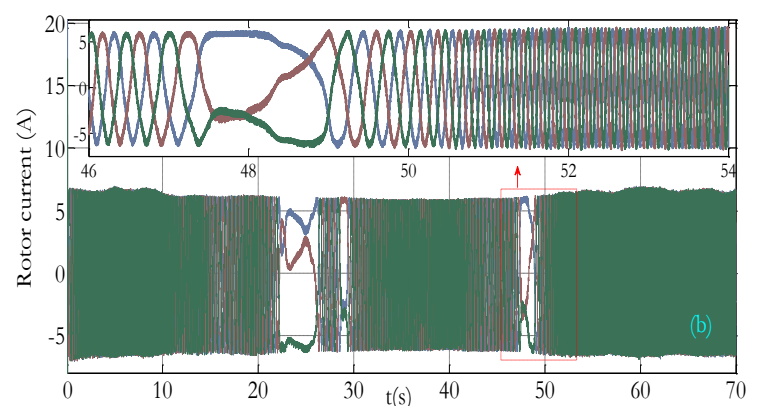

(b)

Figure 20. Behaviour of rotor currents, (a) integral backstepping control, (b) PI control

\section{CONCLUSION}

A nonlinear control strategy for a grid-connected PV-wind hybrid system has been presented. The main control objectives are to guarantee the maximum extraction of locally available renewable energy and to operate the grid-connected hybrid system near unity power factor. The control laws have been developed in the stator-flux oriented reference frame on the basis of Lyapunov's stability theory. The soundness of the proposed control strategy has been confirmed by numerical simulations and its performance was compared to that obtained with a previously proposed one. The results obtained highlight the performance of the proposed nonlinear controller. Future work will concentrate on experimental testing of the proposed control strategy, as well as on improving the control of other renewable energy systems.

\section{REFERENCES}

[1] B. Dursun, C. Gokcol, I. Umut, E. Ucar, and S. Kocabey, "Techno-Economic Evaluation of a Hybrid PV-Wind Power Generation System," International Journal of Green Energy, vol. 10, pp. 117-136, 2013, doi: 10.1080/15435075.2011.641192.

[2] Z. Othman, S. I. Sulaiman, I. Musirin, A. M. Omar, and S. Shaari, "Hybrid Stand-alone Photovoltaic Systems Sizing Optimization Based on Load Profile," Bulletin of Electrical Engineering and Informatics (BEEI), vol. 7, no. 2, pp. 153-160, 2018, doi: 10.11591/eei.v7i2.1171.

[3] G. R. Prudhvi Kumar, D. Sattianadan, and K. Vijayakumar, "A survey on power management strategies of hybrid energy systems in microgrid," International Journal of Electrical and Computer Engineering (IJECE), vol. 10, pp. 1667-1673, 2020, doi: 10.11591/ijece.v10i2.pp1667-1673. 
[4] A. Fathy, K. Kaaniche and T. M. Alanazi, "Recent Approach Based Social Spider Optimizer for Optimal Sizing of Hybrid PV/Wind/Battery/Diesel Integrated Microgrid in Aljouf Region," in IEEE Access, vol. 8, pp. 57630-57645, 2020, doi: 10.1109/ACCESS.2020.2982805.

[5] S. M. M. Aval, and A. Ahadi, "Reliability Evaluation of Wind Turbine Systems' Components," Bulletin of Electrical Engineering and Informatics, vol. 5, no. 2, pp. 160-168, 2016, doi: 10.11591/eei.v5i2.525.

[6] M. Nurunnabi, N. K. Roy, E. Hossain and H. R. Pota, "Size Optimization and Sensitivity Analysis of Hybrid Wind/PV Micro-Grids- A Case Study for Bangladesh," in IEEE Access, vol. 7, pp. 150120-150140, 2019, doi: 10.1109/ACCESS.2019.2945937.

[7] I. Sofimieari, M. W. B. Mustafa, and F. Obite, "Modelling and analysis of a PV/wind/diesel hybrid standalone microgrid for rural electrification in Nigeria," Bulletin of Electrical Engineering and Informatics (BEEI), vol. 8, no. 4, pp. 1468-1477, 2019, doi: 10.11591/eei.v8i4.1608.

[8] W. K. Ahmed, "Aspects in Formulating Mathematical Model of Wind Turbine," Bulletin of Electrical Engineering and Informatics (BEEI), vol. 2, no. 2, pp. 88-94, 2013, doi: 10.11591/eei.v2i2.210.

[9] P. Cheng, H. Nian, C. Wu and Z. Q. Zhu, "Direct Stator Current Vector Control Strategy of DFIG Without PhaseLocked Loop During Network Unbalance," in IEEE Transactions on Power Electronics, vol. 32, no. 1, pp. 284297, Jan. 2017, doi: 10.1109/TPEL.2016.2533638.

[10] Ali Rahnamaei, and Mahdi Salimi, "A Novel Grid Connected Photovoltaic System," Bulletin of Electrical Engineering and Informatics (BEEI), vol. 5, no. 2, pp. 133-143, 2016, doi: 10.11591/eei.v5i2.523.

[11] A. Merabet, K. Tawfique Ahmed, H. Ibrahim, R. Beguenane and A. M. Y. M. Ghias, "Energy Management and Control System for Laboratory Scale Microgrid Based Wind-PV-Battery," in IEEE Transactions on Sustainable Energy, vol. 8, no. 1, pp. 145-154, Jan. 2017, doi: 10.1109/TSTE.2016.2587828.

[12] A. Mahammedi, A. Kouzou, A.Hafaifa, and B. Talbi, "A new technique for a good efficiency of photovoltaic system under fast changing solar irradiation," in Electrotehnica, Electronica, Automatica (EEA), vol. 67, no. 67, pp. 12-19, 2019.

[13] A. Raj and S. S. Dash, "Grid connected hybrid energy system with Maximum power point tracking technique," 2013 International Conference on Energy Efficient Technologies for Sustainability, 2013, pp. 338-342, doi: 10.1109/ICEETS.2013.6533406.

[14] S. Mahjoub, M. Ayadi, F. Masmoudi, and N. Derbel, "Control of Hybrid Renewable Energy System Based on MPPT Strategy Technique," 2018 15th International Multi-Conference on Systems, Signals \& Devices (SSD), 2018, pp. 1280-1286, doi: 10.1109/SSD.2018.8570450.

[15] B. Madaci, R. Chenni, E. Kurt, and K. E. Hemsas, "Design and control of a stand-alone hybrid power system," International Journal of Hydrogen Energy, vol. 41, no. 29, pp. 12485-12496, 2016, doi: 10.1016/j.ijhydene.2016.01.117.

[16] Y. Errami, M. Ouassaid, and M. Maaroufi,"A performance comparison of a nonlinear and a linear control for grid connected PMSG wind energy conversion system," International Journal of Electrical Power \& Energy Systems, vol. 68, pp. 180-194, 2015, doi: 10.1016/j.ijepes.2014.12.027.

[17] B. Housseini, A. F. Okou and R. Beguenane, "Performance comparison of variable speed PMSG-based wind energy conversion system control algorithms," 2017 Twelfth International Conference on Ecological Vehicles and Renewable Energies (EVER), 2017, pp. 1-10, doi: 10.1109/EVER.2017.7935923.

[18] M. El Malah, A. Ba-Razzouk, E. Abdelmounim, and M. Madark, "Robust Nonlinear Sensorless MPPT Control with Unity Power Factor for Grid Connected DFIG Wind Turbines," International Review on Modelling and Simulations, vol. 11, no. 5, pp. 313-324, 2018, doi: 10.15866/iremos.v11i5.15018.

[19] M. Madark, A. Ba-Razzouk, E. Abdelmounim and M. E. Malah, "Nonlinear Controller of Solar PV System for Water Pumping and Irrigation Applications," 2019 International Conference on Wireless Technologies, Embedded and Intelligent Systems (WITS), 2019, pp. 1-6, doi: 10.1109/WITS.2019.8723736.

[20] F. Maissa, O. Barambones, S. Lassad, and A. Fleh, "A robust MPP tracker based on sliding mode control for a photovoltaic based pumping system," International Journal of Automation and Computing, vol. 14, no. 4, pp. 489500, 2016, doi: 10.1007/s11633-016-0982-6.

[21] M. El Malah, A. Ba-Razzouk, M. Guisser, E. Abdelmounim, and M. Madark, "Backstepping based power control of a three-phase Single-stage Grid-connected PV system,"International Journal of Electrical and Computer Engineering (IJECE), vol. 9, no. 6, pp. 4738-4748, 2019, doi: 10.11591/ijece.v9i6.pp4738-4748.

[22] N. Priyadarshi, V. K. Ramachandaramurthy, S. K. Padmanaban, F. Azam, A. K. Sharma and J. P. Kesari, "An ANN Based Intelligent MPPT Control for Wind Water Pumping System," 2018 2nd IEEE International Conference on Power Electronics, Intelligent Control and Energy Systems (ICPEICES), 2018, pp. 443-448, doi: 10.1109/ICPEICES.2018.8897278.

[23] S. -H. Dong, Y. Wang and S. -W. Shu, "A novel Unity Power Factor control strategy based on flux re-orientation for PMSG based wind turbine," 2014 IEEE Conference and Expo Transportation Electrification Asia-Pacific (ITEC Asia-Pacific), 2014, pp. 1-4, doi: 10.1109/ITEC-AP.2014.6941171.

[24] S. Amuthameena, G. Amuthan, L. Ganesan,"Comparative analysis of unity power factor grid-connected PV system with PI and fuzzy-based controllers," International Journal of Power Electronics, vol. 8, no. 2, pp. 159-177, 2017, doi: 10.1504/IJPELEC.2017.082939.

[25] T. Laagoubi, M. Bouzi, and M. Benchagra,"MPPT and Power Factor Control for Grid Connected PV Systems with Fuzzy Logic Controllers," International Journal of Power Electronics and Drive Systems (IJPEDS), vol. 9, pp. 105-113, 2018, doi: 10.11591/ijpeds.v9.i1.pp105-113. 
[26] S. Gallardo, J. M. Carrasco, E. Galvan and L. G. Franquelo, "DSP-based doubly fed induction generator test bench using a back-to-back PWM converter," 30th Annual Conference of IEEE Industrial Electronics Society, 2004. IECON 2004, 2004, pp. 1411-1416 Vol. 2, doi: 10.1109/IECON.2004.1431785.

[27] J. A. Cortajarena, J. De Marcos, P. Alvarez, F. J. Vicandi and P. Alkorta, "Start up and control of a DFIG wind turbine test rig," IECON 2011 - 37th Annual Conference of the IEEE Industrial Electronics Society, 2011, pp. 2030-2035, doi: 10.1109/IECON.2011.6119620.

[28] M. Bouderbala, B. Bossoufi, A. Lagrioui, M. Taoussi, H. A. Aroussi, and Y. Ihedrane,"Direct and indirect vector control of a doubly fed induction generator based in a wind energy conversion system," International Journal of Electrical and Computer Engineering (IJECE), vol. 9, no. 3, pp. 1531-1540, 2019, doi: 10.11591/ijece.v9i3.pp1531-1540.

[29] R. G. Wandhare and V. Agarwal, "Novel Integration of a PV-Wind Energy System With Enhanced Efficiency," in IEEE Transactions on Power Electronics, vol. 30, no. 7, pp. 3638-3649, July 2015, doi: 10.1109/TPEL.2014.2345766.

\section{BIOGRAPHIES OF AUTHORS}
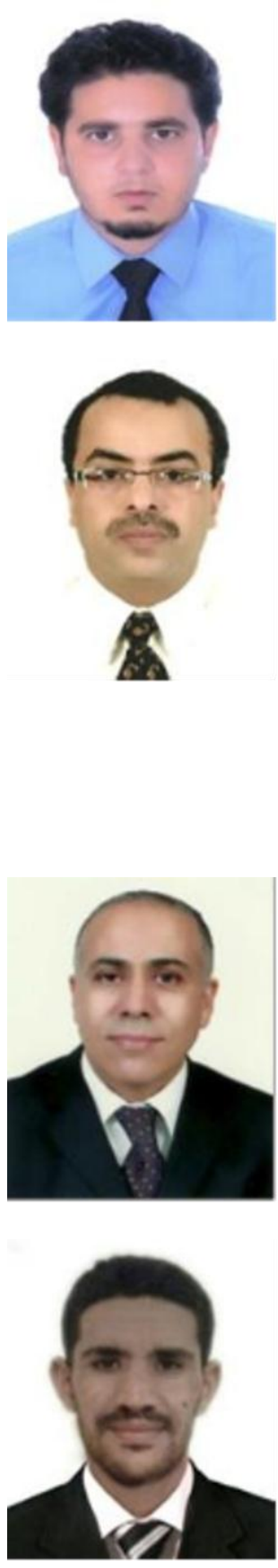

Mohammed El Malah was born in Morocco on November 02, 1980. He received the Master in Automatic, Signal Processing and Industrial Computing from Science and Technical Faculty, Hassan $1^{\text {st }}$ University, Settat, Morocco in 2015. His research consists in the control of the linear and nonlinear systems with use of the advanced controller. Currently, he is preparing his PhD titled "Nonlinear control of renewable energy generation systems" in the Laboratory of System Analysis and Information Processing at Hassan $1^{\text {st }}$ University.

Abdellfattah Ba-Razzouk received the Master's degree (M.Sc.A.) in industrial electronics from the Université du Québec à Trois-Rivières (UQTR), Quebec, Canada, in 1993, and the Ph.D. degree in electrical and computer engineering from the École Polytechnique de Montréal, Quebec, Canada, in 1998. From 1997 to 2003, he was a Lecturer in "motors modelling and control" at the Department of Electrical and Computer Engineering, UQTR. In September 1998, he joined the Hydro-Quebec Industrial Research Chair on Power and Electrical Energy, UQTR, where he has been a Professional Research Scientist working on "high-performance intelligent control of electrical drives". Since June 2009, he is a Professor in electrical engineering with the Department of Applied Physics and a Researcher affiliated to "Systems Analysis and Information Processing Laboratory", both at the Faculté des Sciences et Techniques, Université Hassan 1er of Settat, Morocco. His research interests include high performance control of adjustable speed drives, parameter identification and adaptive control of electrical motors, neural networks, real-time embedded control systems, renewable energy systems, modelling and computer aided design, and real-time simulation of power electronics systems using multiprocessors platforms.

Elhassane Abdelmounim received his $\mathrm{PhD}$ in applied Spectral analysis from Limoges University at science and technical Faculty, France in 1994. In 1996, he joined, as Professor, the applied physics department of the science and technical faculty of Hassan $1^{\text {st }}$ University, Settat, Morocco. His current research interests include digital signal processing and machine learning. He is currently coordinator of a Bachelor of Science in electrical engineering and researcher in "ASTI" System Analysis and Information Technology Laboratory at science and technical faculty, Hassan $1^{\text {st }}$ University, Settat, Morocco.

Mhamed Madark was born in Settat, Morrocco, in 1987. He is a Ph.D. student. He received his B.Sc. degree in mathematics engineering from the Science and Technical Faculty of Hassan $1^{\text {st }}$ University, Settat, Morocco, in 2013, the M.Sc. degree in Automatic, Signal Processing and Industrial Computing from the Science and Technical Faculty of Hassan $1^{\text {st }}$ University, Settat, Morocco, in 2015. His research interests include the adaptive robust nonlinear control of the induction machine and robust nonlinear controller design for three phase grid connected PV systems. 